\title{
Construção de estereótipos do sertão nordestino: das mídias às tatuagens de Kbça, uma análise semiótica
}

\author{
Construction of stereotypes in the \\ northeastern hinterland: from the media to \\ Kbça's tattoos, a semiotic analysis
}

\author{
Fabíola Barbosa Pinheiro \\ Mestranda do curso de Pós \\ Graduação em Desenho \\ Cultura e Interatividade do \\ Departamento de Letras e \\ Artes. Universidade Estadual \\ de Feira de Santana-UEFS, \\ Bahia, Brasil.
}

fabiiola.fsa@gmail.com

\begin{abstract}
RESUMO:
A imagem do sertão nordestino foi construída ao longo dos anos, bem como, estereotipada, e um dos fatores que contribuiu para esse processo foi à mídia. 0 presente artigo tem como objetivo mostrar o processo da produção imagética do sertão nordestino para os brasileiros a partir dos discursos retratados pela mídia, e como todos esses fatores contribuíram para a criação de inúmeros estereótipos que refletem até hoje na representação do sertão nordestino. E no meio desse processo, temos o Kbça um artista nordestino - grafiteiro, tatuador e pintor - que apresenta em suas obras esse sertão imagético repleto de caricaturas estereotipadas, mas que carrega o orgulho do nordestino e dessas imagens que já foram instauradas e perpetuadas pela sociedade como a identidade do ser nordestino. E para compreender como a imagem do Nordeste é apresentada e manifestada nas tatuagens de Kbça, vale-se uma análise de imagem a partir da semiótica.
\end{abstract}

Palavras-chave: imagem; sertão; nordeste; representação; estereótipo.

\section{ABSTRACT}

The image of the northeastern hinterland was built over the years, as well as stereotyped, and one of the factors that contributed to this process was the media. This article aims to show the process of imagery production of the Northeastern hinterland for Brazilians from the discourses portrayed by the media, and how all these factors contributed to the creation of numerous stereotypes that reflect today in the representation of the Northeastern hinterland. And in the middle of this process, we have Kbça, a Northeastern artist - graffiti artist, tattoo artist and painter - who presents in his works this imagery sertão full of stereotyped caricatures, but which carries the pride of the Northeast and these images that have already been established and perpetuated by society as the identity of the Northeastern being. And to understand how the image of the Northeast is presented and manifested in Kbça's tattoos, an image analysis based on semiotics is worth.

Keywords: image; hinterland; northeast; representaction; stereotyped. 


\section{INTRODUÇÃO}

A imagem do Nordeste é um misto de representações, símbolos e mitos, com personagens que marcam a história da região e a torna um grande patrimônio cultural nacional. Ao longo dos anos essa imagem foi construída e reproduzida através de obras célebres literárias, visuais e midiáticas. Com a produção dessa imagem, origina também a estereotipização do Nordeste, reproduzido a partir de discursos da mídia que exprime sua visão do sertão para todo o Brasil.

Essas imagens foram reproduzidas por produções literárias, musicais e audiovisuais, que refletem a percepção imagética que os autores têm do Nordeste, mesclando entre o que foi vivido e imaginado. Algumas dessas produções que são referências na literatura brasileira são dos autores Euclides da Cunha, com Os Sertões e Ariano Suassuna, com 0 auto da compadecida. Literaturas tão marcantes que ultrapassaram os livros para tornarem grandes obras audiovisuais - em questão, 0 Auto da Compadecida - que obteve um alcance nacional e internacional, responsáveis também por compor a imagem do sertão e ultrapassar as fronteiras do Nordeste.

E no meio de toda essa produção imagética, apresento Kbça, um artista plástico, grafiteiro e tatuador que tem como estilo essas figuras do que é o Nordeste. Dentre todas essas expressões artísticas produzidas por Kbça, será utilizado como objeto de estudo as tatuagens, pela sua geração de significados e sentidos que são eternizadas na pele. E para compreender o que esses desenhos significam e como eles caracterizam o Nordeste, será utilizado o método de análise da Semiótica.

\section{REPRESENTAÇÃO IMAGÉTICA DO SERTÃO NORDESTINO}

A palavra sertão está ligada à colonização, interiorização das terras, o oposto ao litoral que com o tempo, vai para além da delimitação espacial, fazendo parte do imaginário nordestino (NEVES, 2003). De modo mais simbólico, retrato o sertão como um lugar de memória que conta a história do seu povo, das crenças e costumes que carrega toda uma rica cultura.

0 sertão nordestino é representado por diversas imagens e figuras icônicas que compõe a história e memória do sertão, como: "a seca do interior, o vaqueiro percorrendo a caatinga, os cangaceiros, fanáticos religiosos, líderes messiânicos, valentões que varam léguas atrás de tirar a ofensa cometida em um forró, os retirantes." (VARJÃO, 2018, p. 517). Esses são apenas exemplos que caracterizam a criação do Nordeste, todas essas particularidades são encontradas em grandes obras que retratam a representação imagética nordestina, obras com teor poético, real e imaginário, clássicos que reproduzem as riquezas culturais, artes e tradições do Nordeste.

São inúmeras produções que podem ser citadas, uma delas é a obra 0 Sertanejo de José de Alencar, um romance que aborda em sua história personagens característicos do sertão, como o protagonista Arnaldo Loureiro, um destemido vaqueiro, simples e muito corajoso. A história se passa no 
estado do Ceará, em um cenário do sertão como uma terra seca, que não há vestígios de água, mas que ainda assim, há sempre os verdes das plantas (ALENCAR, 2000, p.15). O que Alencar propõe em sua obra é que "dentro da paisagem seca persiste o verde, este representando a resistência da vida perante as intempéries do tempo." (OLIVEIRA, 2008, p. 30). É muito forte a imagem da vegetação, a presença dos mandacarus e do solo rachado por consequência das secas.

Outra grande representação imagética do sertão é a figura do cangaço, "um movimento que desde muito tempo é apresentado ao público através do cinema" (VARJÃO, 2018, p. 519), reinava então a figura do rei do cangaço, Virgulino Ferreira da Silva, mais conhecido como Lampião. Essa figura talvez seja a mais emblemática na representação do nordeste, um homem que por ora era muito temido por uns, visto como herói por outros, e ao seu lado, a marcante presença da Maria Bonita, o retrato da mulher valente. "A imagem mítica do cangaceiro está relacionada ao arquétipo do herói, o que divide o bem e o mal, o certo e o errado, enfim os contrários" (OLIVEIRA, 2008, p. 83), uma eterna dicotomia marcada na história do Nordeste. Varjão retrata como "a figura de Lampião está enraizada dentro da memória e cultura popular da região Nordeste, tornando-se uma espécie de objeto-fantástico mesmo depois de sua morte" (2018, p. 519), figura essa, reproduzida em livros, filmes, pinturas e outros.

\section{DO NORDESTE PARA O BRASIL - A MÍDIA COMO PRINCIPAL MEIO DE ESTEREOTIPIZAÇÃO}

Como abordado acima, o sertão Nordestino brasileiro ao longo dos anos foi cenário para grandes obras artísticas, presente nas literaturas, artes plásticas, dramaturgia e outras. São diversos aspectos e contextos que os autores abordam o sertão nordestino, a mídia, por exemplo, - seja através de noticiários, telenovelas ou minisséries - retrata o Nordeste como lugar de miséria, violência, seca e de fome. É a partir de toda essa repercussão na mídia e no âmbito artístico que o sertão nordestino ganhou notoriedade no Brasil, mesmo que de forma negativa.

As imagens que marcam o sertão são de diversas naturezas, e a construção da sua memória e de todos esses estereótipos é originada a partir das histórias e registros visuais que foram capturadas no tempo vivido, como também originada pela mídia, através das suas criações.

Essa imagem retratada pela mídia é responsável pela criação de estereótipos formados e massificados por tantos anos. Para Albuquerque Júnior, toda essa massificação estereotipada são estratégias do discurso midiático, "o discurso da estereotipia, é um discurso assertivo, uma linguagem que leva a estabilidade acrítica, é fruto de uma voz segura e autoconfiante que se arroga o direito de dizer o que o outro é com poucas palavras." (2008, p. 20).

Hoje, a sociedade está pautada e dominada pelo processo midiático. As mídias têm feito cada vez mais parte do cotidiano das pessoas, assim, a 
sociedade gira em torno das mídias e em tudo que elas têm a oferecer, "a mídia é o principal lugar de memória e/ou história das sociedades contemporâneas" (RIBEIRO, 2003).

Em uma sociedade dos meios, as mídias estão em contato com os demais campos sociais, que predomina a cultura midiática, convertida em referência sobre a qual a estrutura sociotécnica-discursiva se estabelece, produzindo zonas de afetação em vários níveis da organização da própria sociedade. Logo, o discurso reproduzido pela mídia gera grande impacto no indivíduo, afetando a grande massa que forma ideias e opiniões pautadas em seu discurso, promovendo o diálogo entre diversos campos sociais, já que "os campos sociais necessitam da mídia para garantir visibilidade frente à esfera pública e a mídia necessita dos demais campos para colocar em prática sua visibilidade" (SANCHOTENE, 2009, p. 251). E toda essa visibilidade interfere no modo que a sociedade ver/julga determinados assuntos.

A mídia tem grande impacto no indivíduo e na sociedade como um todo, isso porque ela desempenha o papel de enunciadores da informação, "nela se percebe um processo de significação que contempla a construção do discurso nas suas diversas configurações - tanto construções verbais como não verbais (por imagens, gestos e ações)" (GOMES, 2016). Essas construções, por vezes, aborda uma visão exagerada e generalizada de algo, com foco aqui, da cultura nordestina, são as hipérboles que desencadeiam o estereótipo, que para Albuquerque Júnior,

\section{É um olhar e uma fala produtiva, ele tem um dimensão concreta, porque, além de lançar mão de matérias e formas de expressão sublunar, ele se materializa ao ser subjetivado por quem é estereotipado, ao criar uma realidade para o que toma como objeto. (2008, p. 20)}

É dessa forma que o Nordeste se apresenta para as outras regiões do Brasil, carregados de simbolismos, imagens e representações demasiadas. Albuquerque (2001) convida o leitor a olhar o Nordeste através da mídia, seja em filmes, novelas, jornais e principalmente em programas de humor, "o que geralmente aparece em cena é um lugar bem distante (de quem?), com pessoas engraçadas, que falam errado, se vestem com roupas emendadas, usam maquiagem exagerada, dão tiro e peixeiradas para todo lado..." (VASCONCELOS, 2006, p. 06). 0 discurso por trás dessas imagens, é um retrato que o nordestino, não se reconhece, mas é como ele é representado.

Há um longo embate de representação, que surge também da disputa Norte e Sul, seja ele políticos ou históricos, ao longo dos anos essa imagem da miséria e seca foi construída, mas que na modernidade, aos poucos, tem se tornada menos estereotipadas e mais reais. 


\section{ANÁliSE SEMIÓtICA DAS TATUAGENS DE KBÇA E SUA REPRESENTAÇÃO DO NORDESTE}

Quando discutimos sobre a imagem do Nordeste vêm todas as caricaturas e exageros que foram construído e eternizado ao longo dos anos, e boa parte dessa imagem, como já foi dito, incumbiu-se a mídia. Essa imagem é tão poderosa e foi tão massificada que artistas reproduzem em artes visuais, e um desses artistas é o Kbça, que carrega em seus traços essas figuras do que é o Nordeste.

Esse estilo que ele produz é fruto do orgulho que tem em ser nordestino, e várias pessoas compartilham desse mesmo pensamento e fazem tatuagens com esses desenhos que identificam o Nordeste. Mesmo com o objetivo de enaltecer sua região, essa dissipação da imagem da seca, messianismo e "brabeza" que é presente em suas tatuagens, só reforça o estereótipo de um Nordeste monocultural, mas que na verdade, possui uma grande pluralidade de culturas, que diferenciam até mesmo dentro de um próprio estado. Mas para compreender como o Nordeste é apresentado nas tatuagens de Kbça, faz-se necessário uma análise semiótica, para entender o significado de cada elemento que compõe o desenho.

A semiótica é um método de análise pautado no estudo dos signos e nos processos de significação que atribuímos aos objetos. Segundo Santaella (1985, p. 15) "a semiótica é a ciência que investiga todas as linguagens possíveis, ou seja, tem como objetivo o exame dos modos de constituição de todo e qualquer fenômeno como fenômeno de produção de significação e de sentido", sejam essas linguagens verbais ou não verbais, como música, gestos, fotografias, desenhos e outros. Conceituando o signo, objeto e interpretante, Charles Sanders Peirce - fundador do pragmatismo e da ciência dos signos diz:

\footnotetext{
Um signo, ou representamen, é aquilo que, sob certo aspecto ou modo, representa algo para alguém. Dirige-se a alguém, isto é, cria na mente dessa pessoa um signo equivalente, ou talvez, um signo mais desenvolvido. Ao signo criado, denomino interpretante do primeiro signo. O signo representa alguma coisa, seu objeto. Representa esse objeto não em todos os seus aspectos, mas com referência ao tipo de ideia que eu, por vezes, denominei fundamento ou representamen. (PEIRCE, apud SANTAELLA, 1995, p. 23).
}

Na semiótica de Peirce, de acordo com a sua segunda tricotomia, um signo, referente a o nível de objetivação, pode ser denominado por três categorias: índice, ícone e símbolo, sendo que cada uma dessas características se refere a um objeto. E para fundamentar essa afirmação, e necessário apresentar o conceito de cada um desses signos.

0 ícone é o signo que representa seu objeto a partir de sua semelhança. É a forma mais eficiente de comunicar diretamente uma ideia, pois, representam os objetos como eles realmente são. Como exemplo, Peirce (2010) cita a fotografia, 
Especialmente as do tipo "instantâneo" são muito instrutivas, pois sabemos que, sob certos aspectos, são exatamente como os objetos representam. Esta semelhança, porém, deve-se ao fato de terem sido produzidas em circunstâncias tais que foram fisicamente forçadas a corresponder ponto por ponto a natureza." (PEIRCE, 2010, p. 65).

0 índice é o signo que estabelece a associação de uma situação ao objeto, através de uma experiência adquirida, como o nome já diz indica circunstâncias do fato. Peirce utiliza exemplos como: uma batida na porta, que indica que alguém está do lado de fora e "um homem que anda gingando. Isso é uma indicação provável de que é marinheiro". (PEIRCE, 2010, p. 67).

Por fim, o símbolo é um signo abstrato, na qual se refere ao objeto através de associações, a sua forma não necessariamente tem relação de semelhança com objeto, por isso, é necessário aprender o que eles significam. "O símbolo é aplicável a tudo que possa concretizar a ideia ligada à palavra; em si mesmo, não identifica essas coisas.” (PEIRCE, 2010, p. 73).

A semiótica ajuda a entender a construção de significados dos fenômenos de expressão da linguagem humana (SANTAELLA, 1986), sendo a linguagem abordada no projeto, o desenho. Para Gomes, (1996, p.13) “o desenho é uma das formas de expressão humana que permite a representação das coisas concretas e abstratas que compõem o mundo natural ou artificial em que vivemos", e a partir das representações será possível interpretar as tatuagens de Kbça, buscando identificar o ícone, índice e os símbolos que se associam ao sertão.

Abaixo, algumas obras do artista:

Figura 1: "mãe"

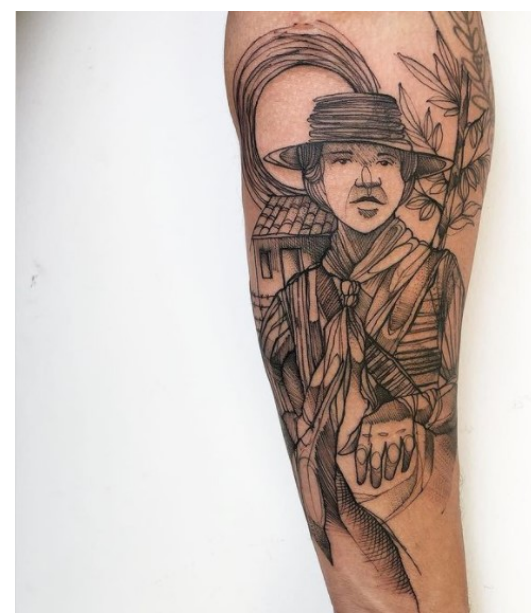

Fonte: Instagram @one_kbca, 2020. 
Figura 2: "História de fé e raízes histórias de lutas e glórias"

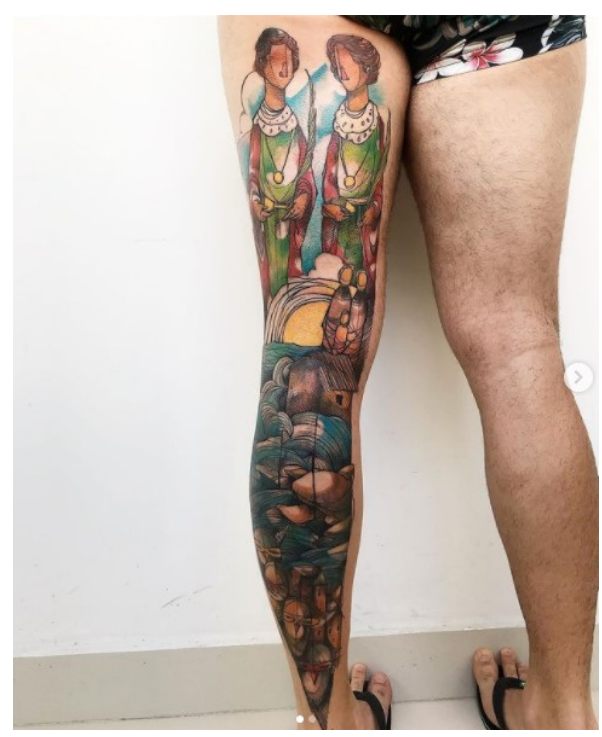

Fonte: Instagram @one_kbca, 2020.

Figura 3: "Cangaço"

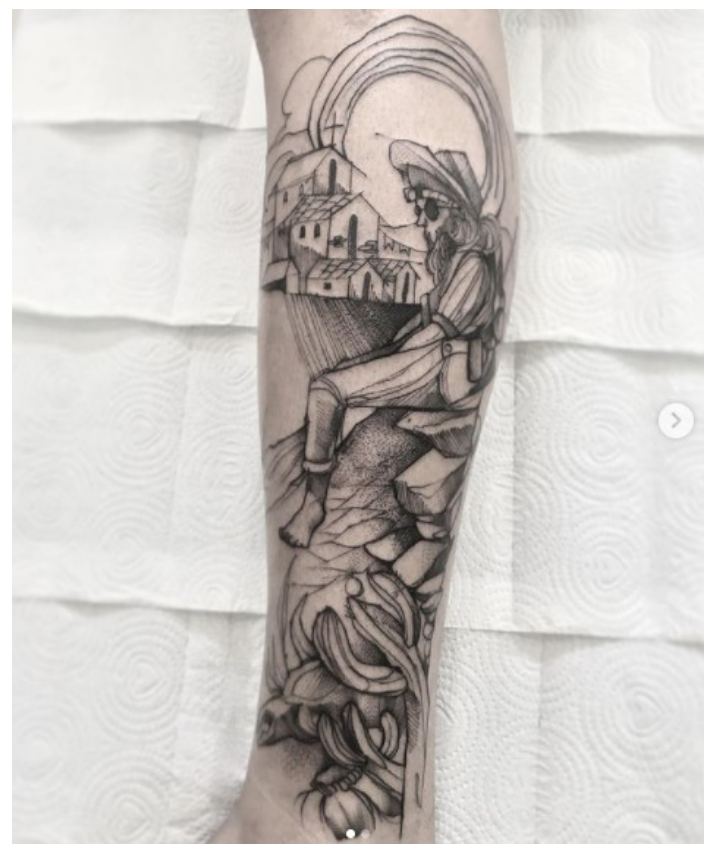

Fonte: Instagram @one_kbca, 2020.

São diversas tatuagens feitas por Kbça, e cada uma delas cabe uma análise minuciosa para compreensão e referência com o Nordeste. Porém, para esse artigo será feito uma breve análise semiótica de apenas uma tatuagem, a figura 3.

Essa tatuagem é repleta de signos e significados que exprimem a cultura Nordestina, isso porque temos em primeiro plano uma grande figura 
icônica, o famoso cangaceiro, é considerado um ícone, pois está representando aquilo o que realmente é. Pinturas, fotografias e desenho são as artes visuais mais comuns que configura o ícone (hipoícones), pois são signos puros, segundo Nöth (1995) apud Wanner (2010), "um ícone puro é um signo que serve "como signo pelo fato de ter uma qualidade que o faz significar". Em vista disso, o ícone puro pode apenas constituir "um fragmento de um signo mais completo"'” (2010, p. 40), eles significam exatamente o que exibe.

Na tatuagem, é possível identificar que o personagem do desenho é um cangaceiro a partir dos acessórios, o chapéu do personagem é uma das marcas do cangaço, em especial do bando liderado por Virgulino Ferreira da Silva, Lampião, o cangaceiro mais famoso do Brasil, que se preocupava também com a imagem visual do seu bando, "e se há no cangaço um elemento épico, este é ainda exacerbado pelos trajes e equipagem dos cangaceiros" (SUASSUNA apud CHAVES, 2018, p. 47). O chapéu retratado no desenho é o típico chapéu de couro "com abas largas e erguidas em meia lua repleta de signos sagrados ou místicos, carregado de moedas e peças de metal de diversas ordens é o ponto alto que caracterizava o traje do cangaceiro" (CHAVES, 2018, p. 50), que buscava a composição de adornos místicos (como proteção) e estéticos.

Ao analisar outros aspectos da imagem, nota-se uma cruz, esse elemento é um símbolo, um signo cultural que possui significados que são aprendidos e determinados, que na cultura cristã é uma alusão a Jesus Cristo, pelo seu sacrifício na cruz. Esse símbolo é o significado mundial do cristianismo, mas porque ele é uma referência para o Nordeste? Essa associação é gerada a partir das condições do nordestino, sempre em busca de uma resposta para as dificuldades sofridas, a religiosidade "deu forma a suas esperanças, expectativas, imaginações, medos, alegrias, dúvidas conscientes ou inconscientes" (LENAERS, 2011, p. 16, apud PONTES, 2014, p. 157), na qual eles buscavam o paraíso verde, o oposto da terra seca e semiárida que estavam habituados.

A religião para o nordestino é "o imaginário dessa possível travessia para a ansiada vida plena”, (PONTES, 2014, p. 157), que marcava o fim da vida sofrida, para o renascimento de uma vida farta e alegre.

E por fim, o índice, "um signo que se refere ao seu objeto que denota em virtude de ser realmente afetado por esse objeto" (PEIRCE, 2010, p. 52), corresponde a uma relação causal com o objeto, pois ele indica algo. No desenho, o chão rachado indica a seca, ocasionado pela recorrente falta de chuva que atinge oito dos nove estados do Nordeste. A imagem da seca nordestina foi criada e propagada por estratégias políticas que se beneficiaram com esse cenário infértil, onde os meios de comunicação se encarregaram de difundir ainda mais essa ideia.

Os períodos de estiagem são "associadas às imagens de chão rachado, plantação seca, gado morto e pessoas passando fome, que corroboram com as representações simplórias e caricatas do nordestino." (BARBOSA, PEREIRA, p. 131), por isso que esse aspecto se tornou parte da composição imagética do 
Nordeste, é quase impossível ver uma imagem da seca e não associar ao Nordeste. E a tatuagem aborda todos esses elementos, a cabeça do gado e a flora propícia da seca.

Essa tatuagem é tão rica em detalhes que são inúmeros os pontos que podem ser analisados pela semiótica, esses citados, são alguns dos principais aspectos quando se trata da imagem construída - e estereotipada - do Nordeste.

Essas construções imagéticas são frutos de apreciações superficiais sobre a realidade do semiárido brasileiro, de seus habitantes e dos interesses políticos das elites locais que procuram explicar o subdesenvolvimento da região como resultado de condições naturais adversas e da formação de sua gente (SILVA, 2003 apud BARBOSA, PEREIRA, p. 132).

\section{CONSIDERAÇÕES FINAIS}

Em meio à história do sertão nordestino, podemos observar como ocorreu o processo de construção da sua imagem, que foi a partir de abordagens e manifestações de diversos autores e atores, expressados tanto por uma visão documental quanto ficcional, vivida ou imaginada, dotada de símbolos, imagens e significados que traduzem o imaginário nordestino, colocando em pauta a dicotomia do estereótipo e original, dicotomia essa que pôde ser percebida a partir da exposição da mídia tradicional e literária que explanaram sobre esse tema e contribuíram para a "invenção do Nordeste".

A conclusão diante de tudo que foi apresentado e discutido é que o Nordeste, mesmo depois de tantos avanços e assistências, será marcado na memória do brasileiro como um lugar de seca, fome e fanatismo religioso, na qual muitos nordestinos guardam o sentimentalismo e saudosismo, em forma de orgulho e em outra face muitos nordestinos que não se sentem representados e sente a necessidade de ressignificar essa imagem massificada. Porém, até serem descontruídas, essas imagens continuarão sendo a "cara" do Nordeste.

\section{REFERÊNCIAS BIBLIOGRÁFICAS}

ALBUQUERQUE JUNIOR, Durval Muniz de. A Invenção do Nordeste e outras artes. São Paulo: Cortez. 2006.

ALENCAR, José de. O Sertanejo. São Paulo: Escala, 2000. (Coleção Grandes Mestres da Literatura Brasileira).

CHAVES, Luciano Gutembergue Bonfim. A Estética do cangaço à luz das noções nietzscheanas de apolíneo e dionisíaco. Analógos - 2018, n. 1. 0.17771/PUCRio.ANA.34414

GOMES, Luiz Vidal Negreiros. Desenhismo. Santa Maria: Editora da UFSM, 1996. 
GOMES, Pedro Gilberto. Midiatização: um conceito, múltiplas vozes. Porto Alegre: Ed. Famecos, v. 23, n. 2, 2016.

NEVES, Erivaldo Fagundes. Sertão Como Recorte Espacial e como Imaginário Cultural. Politeira: hist. e soc. Vitória da Conquista. V. 3, n.1, 2003.

OLIVEIRA, Gilsimar Cerqueira de. Histórias em Quadrinhos e a Representação Social do Nordeste e do Nordestino Brasileiro: Imagem e Imaginário na Consolidação do Visível e do Dizível. Feira de Santana, 2008. Dissertação (Mestrado em Desenho, Cultura e Interatividade) Feira de Santana - Bahia.

PEIRCE, Charles Sanders. Semiótica. 1839 - 1914. [tradução José Teiceira Coelho Neto]. - 4 ed. - São Paulo: Perpesctiva, 2010. (Estudos; 46/dirigda por J. Guinsburg).

PEREIRA, Adriana dos Santos Pereira. BARBOSA, José Roberto Alves. (SER)tão nordestino na sala de aula: Um novo desenho situado de ensino. Revista Lampejo - vol. $9 \mathrm{n}^{\circ} 1$ - issn 2238-5274

PONTES, Emilio Tarlis Mendes. Fé e pragmatismo no sertão. Mercator, Fortaleza, v. 13, n. 2, p. 155-168, mai./ago. 2014. ISSN 1984-2201. 2002, Universidade Federal do Ceará.

RIBEIRO, Ana Paula Goulart. A mídia e o lugar da história. Rio de Janeiro: Lugar Comum, n 11, pp. 25-44, 2003.

SANCHOTENE, Carlos Renan Samuel. A midiatização como processo de reconhecimento, legitimidade e prática social. As mitologias do sertão através do cinema e literatura. Emancipação, Ponta Grossa: Ed. Unisinos, p.249-258, 2009.

SANTAELLA, Lúcia. O que é semiótica. $4^{a}$ edição. São Paulo: Brasiliense, 1986.

VARJÃO, Thiago de Brito. As mitologias do sertão através do cinema e literatura. Letras de Hoje, v. 53, n. 4, p. 517-525, 2018.

VASCONCELOS, Cláudia Pereira. A construção da imagem do nordestino/sertanejo na constituição da identidade nacional. II ENECULT Encontro de Estudos multidisciplinares em Cultura. Faculdade de Comunicação/UFBA. Salvador - BA - 05/05 a 05/05/2006.

WANNER, Maria Celeste de Almeida. Paisagens sígnicas: uma reflexão sobre as artes visuais contemporâneas - Salvador: EDUFBA, 2010.

Artigo recebido em 01/07/2021 e aceito em 10/12/2021

Este artigo está licenciado sob forma de uma licença Creative Commons Atribuição 4.0 Internacional, que permite uso irrestrito, distribuição e reprodução em qualquer meio, desde que a publicaçåo original seja corretamente citada.

https://creativecommons.org/licenses/by/4.0/deed.pt BR. 